\title{
Metastatic bone disease of the pelvis and extremities: Rationalising orthopaedic treatment
}

Maria N. Kirkinis BBiomed ${ }^{\mathrm{a}}$, Tim Spelman BSc, MBBS ${ }^{\mathrm{b}}$, Deborah May BN, Grad Cert Ortho ${ }^{\mathrm{c}}$,

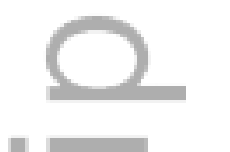

Peter F.M. Choong MBBS, MD FRACS, FAOrthA ${ }^{\mathrm{a}, \mathrm{b}, \mathrm{c}}$

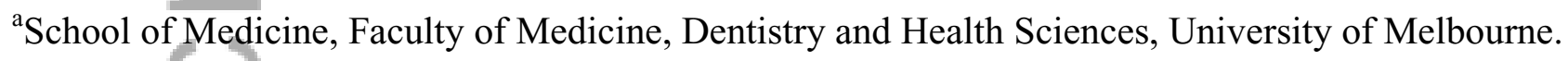

${ }^{\mathrm{b}}$ University of Melbourne Department of Surgery St. Vincent's Hospital Melbourne.

${ }^{c}$ Department of Orthopaedics, St Vincent's Hospital Melbourne

Figures and tables: Three figures, two tables, one supplementary table

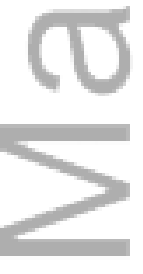

Word count: Abstract 188 words, Text 2225 words

\section{Corresponding Author:}

Professor Peter F.M. Choong

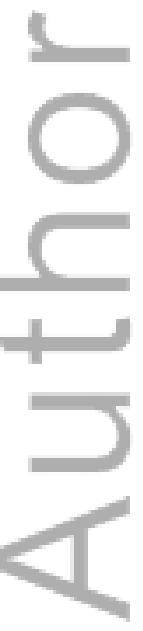

\section{pchoong@unimelb.edu.au}

Level 2, Clinical Sciences Building

29 Regent Street, Fitzroy 3065, Victoria, Australia

t: +61392312365 | f: +61392312571 |

\section{$\underline{\text { Running title: Fixation of metastatic disease of bone }}$}

This is the author manuscript accepted for publication and has undergone full peer review but has not been through the copyediting, typesetting, pagination and proofreading process, which may lead to differences between this version and the Version of Record. Please cite this article as doi: 10.1111/ans.13615

This article is protected by copyright. All rights reserved. 


\begin{abstract}
$\underline{\text { Abstract }}$
Background: Choosing the appropriate treatment for patients presenting with impending or pathological fractures is difficult and understanding the prognosis based on certain characteristics can help inform the decision to treat and construct to use in a palliative setting. We retrospectively analysed patients presenting with metastatic bone disease in the extremities and pelvis.

Methods: Patients presenting with metastatic bone disease to the extremities or pelvis whom underwent orthopaedic treatment from 1996 - 2012 were identified. Survival rates were calculated using life table analysis. Univariate and Multivariate analysis was achieved with Cox proportional hazards regression.

Results: There were 462 patients. An overall 1, 2 and 5-year survival rate of 45\%, 29\% and 13\% was identified, respectively. In the multivariate analysis preoperative haemoglobin was found to be an independent predictor of better survival while lung histotype, age, pathological fracture and previous combined therapy were negative predictors of survival. Patients undergoing prosthetic replacement had a significantly longer period of hospitalisation in comparison to those undergoing internal fixation.
\end{abstract}

This article is protected by copyright. All rights reserved. 
Conclusion: This study has contributed to our understanding of the survival rate and survival prognostication for patients presenting for orthopaedic treatment of metastatic bone disease.

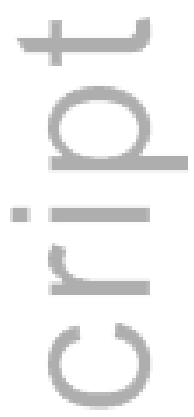

\section{Introduction:}

Patients presenting with pathological or impending fractures due to metastatic lesions have a variable survival. Two large studies looking at metastasis to the extremities and pelvis have identified a 1 year survival rate of $39 \%{ }^{1}$ and $41 \%{ }^{2}$. Choosing the appropriate orthopaedic treatment that does not impose long rehabilitation periods but still offers a durable construct can be difficult. Studies have reported on the predictive nature of a range of factors, including pathological fracture where it was found to be an independent predictor of poorer prognosis ${ }^{1,3,4}$. Understanding the predicted survival in relation to certain patient and procedure factors can help demystify the choice of construct.

We retrospectively analysed patients presenting with metastatic bone disease to the extremities and pelvis. Our main objective was to determine survival rates and prognostic factors. Overall, this study will contribute to the literature regarding survival prognostication for patients with metastatic bone disease.

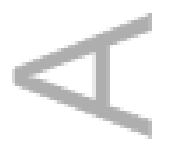

This article is protected by copyright. All rights reserved. 


\section{可}

要

(1)

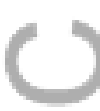

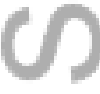

כ

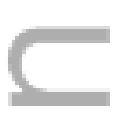

\section{Materials and Methods:}

\section{Participants:}

Patients presenting for surgery of metastatic bone disease to the extremities or pelvis from $1996-$ 2012 were identified from the St Vincent's Orthopaedic Tumour Registry. This resulted in 564 cases. We excluded cases if the location of the metastasis was not osseous $(n=12)$ or if the location was not in the extremities or pelvis $(n=1)$. Cases where only a biopsy had taken place $(n=10)$ and where radiofrequency ablation was used $(n=1)$ were also excluded. Cases where the surgery was abandoned $(\mathrm{n}=1)$ or the diagnosis was of a primary bone tumour $(\mathrm{n}=1)$ were excluded. Two patients without follow up data were excluded $(n=2)$, where one of the patients did not have the procedure. One patient was repeated within the database $(n=1)$ and was excluded. One patient had both an internal fixation and prosthetic replacement on the same side and in the same procedure, but only contributed once to the cohort for the prosthetic replacement. Where participants had bilateral

This article is protected by copyright. All rights reserved. 
reconstructions they contributed twice to the initial cohort $(n=3)$, resulting in 538 cases. Duplicates were then excluded from the statistical analysis $(n=76)$. This resulted in a total of 462 observations. Two observations ended on the date of surgery and were excluded from the prognostication analysis.

\section{Procedure:}

This was a retrospective study design. The variables included in the statistical analysis were type of metastatic histotype, age at diagnosis, American Society of Anestheologists (ASA) score ${ }^{5}$, pathological fracture, previous therapy, location of the metastasis, preoperative haemoglobin, type of procedure, whether en bloc resection or curettage had occurred and postoperative radiotherapy and chemotherapy. Age at diagnosis was categorised into patients below 65 years and patients 65 years and above for analysis. Follow up data was collected from last known date of contact through review appointments or correspondence. The date of death was recorded through notification to the institution from family, other health facilities or from Cancer Council Victoria.

\section{Statistical analyses:}

Categorical variables were summarised using frequency and percentage. Continuous variables were summarised using mean and standard deviation (SD) or median and interquartile (IQR) ranges as appropriate. Survival rates were calculated using life table analysis. Kaplan-Meier methods were used to determine the survival estimate curve. Cox Proportional Hazards Regression was utilised for univariate and multivariate analysis. A two-sided test was used with a significant $\mathrm{p}$ value of less than 0.05 . The hazard proportionality for the multivariate analysis was tested with the use of scaled

This article is protected by copyright. All rights reserved. 
Schoenfeld residuals. Analyses were conducted using Stata version 13 (StataCorp, College Station, Texas).

\section{Ethics:}

Ethics approval was obtained from St Vincent's Melbourne Human Research Ethics Committee and St Vincent's Private Hospital Human Research Ethics Committee.
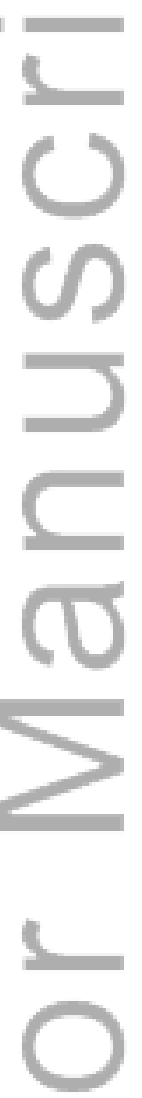

\section{$\underline{\text { Results: }}$}

\section{Patient and Procedure Characteristics:}

There were $258(56 \%)$ females and 204 (44\%) males with a median age at diagnosis of 64 years $(\mathrm{IQR}=55,72) .249(54 \%)$ patients were below 65 years and $213(46 \%)$ patients were 65 years or older.

This article is protected by copyright. All rights reserved. 
$155(34 \%)$ patients presented with a pathological fracture. All patients underwent orthopaedic treatment for either a metastatic lesion or pathological fracture in the extremities or pelvis. The locations are depicted in figure 1. Where patients had lesions both in the pelvis and in the femur they were classified as pelvis $(n=23)$. The different metastatic histotypes are shown in Figure 2 .

$205(44 \%)$ patients underwent internal fixation and $230(50 \%)$ patients underwent prosthetic replacement. Other procedures such as amputation $(n=2,0.4 \%)$, girdlestones $(n=4,0.9 \%)$ and excision alone with or without allograft $(n=5,1.1 \%)$ or curettage alone with bone graft or cement $(\mathrm{n}=5,1.1 \%)$ were also included in the analysis. Internal hemipelvectomy/sacrectomy $(\mathrm{n}=14.3 .0 \%)$ was included, where 3 patients were also treated with prosthetic reconstruction.

When looking at type of resection 54 patients underwent En bloc resection (12\%) and 54 underwent curettage (12\%).

Prior to surgery, patients either had nil therapy $(n=202,44 \%)$, chemotherapy $(n=42,9.1 \%)$, radiotherapy $(n=89,19 \%)$ or combined chemotherapy and radiotherapy $(n=125,27 \%)$. All adjuvant radiotherapy was to the fixated bone. Previous therapy was unknown in $4(0.9 \%)$ cases.

Postoperative therapy included radiotherapy $(n=294,64 \%)$, which was unknown in 13 cases $(2.8 \%)$ and chemotherapy ( $\mathrm{n}=114,25 \%)$, which was also unknown in 13 cases $(2.8 \%)$.

The ASA categories found were ASA $1(n=5,1.1 \%), 2(n=53,11 \%), 3(n=187,40 \%)$ and 4 $(n=106,23 \%)$. There were $111(24 \%)$ ASA values missing. Preoperative haemoglobin was examined and a median of $122 \mathrm{~g} / \mathrm{L}(\mathrm{IQR}=108,134)$ was found. There were $32(6.9 \%)$ observations missing.

\section{Survival Analysis:}

This article is protected by copyright. All rights reserved. 
The median follow up was 0.72 years (IQR $0.27,2.0$ ). The overall survival rate was $45 \%$ at 1 year, $29 \%$ at 2 years and $13 \%$ at 5 years. The Kaplan-Meier survival estimate curve is shown in figure 3. Further median survival analysis has been calculated for each univariate variable and has been included in Table S1. Overall, 29 patients died within 1 month of follow up. The highest frequency of early mortality looking at metastatic histotype was lung cancer patients ( $n=11,38 \%)$.

\section{Univariate Analysis:}

The results of the unadjusted model are summarised in table 1.

\section{Multivariate Analysis:}

These results are summarised in table 2 . The hazards proportionality for the multivariate analysis was tested with the use of scaled Schoenfeld residuals, finding a global test value of 0.1569 .

\section{Morbidity Outcomes:}

Following surgery, the median length of stay was 8 days (IQR 5, 14). There were 379 observations for length of stay. The median length of stay in the internal fixation group was 6 days (IQR 4, 11) with 183 observations and in the prosthesis group 10 days (IQR 6, 15) with 180 observations, p value $<0.0001$

Furthermore, Five (1.1\%) patients had a fracture following the initial surgery. Three of the fractures were in the internal fixation group and 2 in the prosthetic replacement group.

\section{Discussion:}

This article is protected by copyright. All rights reserved. 
The overall 1, 2 and 5-year survival rate of $45 \%, 29 \%$ and $13 \%$ is similar to other published survival rates for large studies. Ratasvuori et al. ${ }^{2}$ identified a 1-year and 5-year survival rate of $41 \%$ and $2 \%$, respectively. Hansen et al. ${ }^{1}$ used the same tumour registry at a different time and found a 1 , 2 and 3 -year survival rate of $39 \%, 26 \%$ and $18 \%$, respectively. Dijstra et al. ${ }^{6}$ found a 1 -year survival rate of $40 \%$.

On univariate analysis patients presenting with a pathological fracture were found to have a poorer predicted survival associated with 1.57 times the rate of death relative to having no pathological fracture. Hansen et al. ${ }^{1}$ looked at metastatic bone disease in the extremities and pelvis and also reported pathological fracture to be significant on univariate analysis. Other studies have also reported this finding, however, focus specifically on patients presenting with metastatic bone disease from specific primary tumours ${ }^{4,7-10}$ and looking at metastasis to both the appendicular and axial skeleton ${ }^{11}$ or the femur alone ${ }^{3}$. Ratasvuori et al. ${ }^{2}$ looked at 1107 cases and no significant difference was found in the survival prognostication of patients presenting with pathological fracture or impending fracture but reported a trend towards those with impending fractures having a median survival better than those with pathological fractures. Schneiderbauer et al. ${ }^{12}$ also found no significant difference. However, this study has exclusively reported on patient survival after hip arthroplasty for metastatic bone disease. Finally, multivariate analysis has identified pathological fracture to be an independent predictor of poorer survival in this study. This has also been identified in a number of studies ${ }^{1,3,4}$. Hansen et al. ${ }^{1}$, with a similar sample size, also found pathological fracture to be an independent predictor of survival.

Breast and gynaecological histotypes were found to be positive predictors of survival on univariate analysis. Lung and prostate histotypes were significant negative predictors of survival. 
Hansen et al. ${ }^{1}$ found that patients presenting with metastatic disease from lung, prostate or unknown cancer had a poorer prognosis on univariate analysis, while breast, kidney and myeloma and lymphoma cancer was found to predict a better survival. While our study agrees with the findings of breast, lung and prostate cancer to be significant on univariate analysis, renal and haematological histotype were not significant. On multivariate analysis lung metastatic histotype was identified as an independent predictor of poorer survival. Hansen et al. ${ }^{1}$ has also identified lung cancer to be a negative predictor of survival and myeloma as a positive predictor of survival while Ratasvuori et al. ${ }^{2}$ found breast cancer, kidney cancer, thyroid cancer, myeloma and lymphoma to be predictors of survival. There is some inconsistency in these results. However, these studies were conducted with different patient populations and this as well as selection bias may be contributing.

Preoperative haemoglobin has been found to be a positive predictor of survival both on univariate and multivariate analysis. This has also been recognised in a number of studies on univariate $^{1,4,13-15}$ and multivariate analysis ${ }^{1,13,15}$. Preoperative haemoglobin may be prognostic as a marker of cancer burden.

An ASA score of 2 on univariate analysis was found to be a positive predictor of survival. This was in relation to an ASA score of 4 and may suggest those with a better physical status are more likely to do well. However, this was not significant on multivariate analysis and 111 ASA results were unknown. Interestingly males were found to have 1.37 times the rate of death as compared to females on univariate analysis. Gender did not continue to show significance on multivariate analysis. However, the patient population in relation to gender was not equal with 258 females and 204 males. Hansen et al. ${ }^{1}$ did not find any difference in the survival between male and female patients. Age was found to be a negative predictor of survival on univariate and multivariate 
analysis. This was not found to be significant by Hansen et al. ${ }^{1}$. Other studies looking at specific tumours have found age to be significant on univariate ${ }^{7,13,16}$ and multivariate analysis ${ }^{8,13,16}$.

Patients whom had received combined chemotherapy and radiotherapy preoperatively were predicted to have a poorer survival both on univariate and multivariate analysis. This may represent patients with a higher cancer burden undergoing this course of treatment. Postoperative adjuvant therapy was not found to be significant on univariate analysis.

Location of metastasis in the femur and pelvis were also found to be significant negative and positive predictors of survival on univariate analysis, respectively. In the multivariate analysis neither were found to be independent predictors of survival.

Regarding procedure characteristics, prosthetic replacement was found to decrease the rate of death by $41 \%$ compared to internal fixation on univariate analysis. Type of procedure did not continue to be an independent predictor of survival on multivariate analysis. Loss of significance may suggest that the procedure chosen in part reflects assessment of a patients' likely survival by the surgeon. This was also not found to be significant by Hansen et al. ${ }^{1}$ Regarding outcome, the fracture rate in this cohort was low at $1.1 \%$. This suggests a low rate of fracture and may signify success of fixation. However, as the patient cohort has a low survival postoperatively, there may not be enough time to fully determine the rate of fracture. Looking at length of stay, patients undergoing prosthetic replacement had a significantly longer length of hospitalisation than those undergoing internal fixation and may signify the importance of choosing a construct predicted to have a shorter length of stay for patients likely to experience an early mortality, such as lung cancer patients. Finally, wide en bloc resection showed a significantly better prognosis on univariate analysis but did not show significance on multivariate analysis. 
Overall, consistency in multivariate analysis has been found with this study and in similar studies within the literature, specifically relating to pathological fractures, presence of lung metastatic bone disease, preoperative haemoglobin and age at diagnosis. This may suggest that these factors need to be considered when choosing the best treatment to maintain and improve quality of life.

Overall, the limitations associated with this study are its retrospective study design. Some data was unavailable and patients may have been followed up elsewhere. Selection bias may have also occurred. However, this study contains a large number of participants and shows some consistency with other similar studies in the literature.

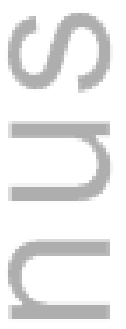

\section{Conclusion:}

This study has highlighted a number of prognostic factors associated with survival in patients presenting with metastatic bone disease. However, the palliative nature of this condition presents a limitation to the design of studies into metastatic bone disease and this must be taken into consideration. Overall, this study has contributed to our knowledge of metastatic bone disease to the extremities and pelvis.

\section{Acknowledgements}

Thank you to Dr Lester Chan for the provision of bone diagrams.

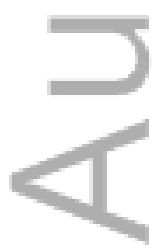




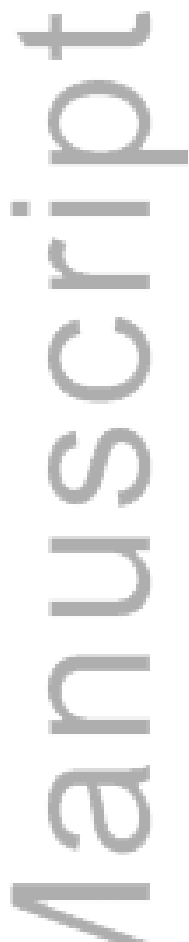

\section{References:}

[1] Hansen BH, Keller J, Laitinen M, et al. The Scandinavian Sarcoma Group skeletal metastasis register: Survival after surgery for bone metastases in the pelvis and extremities. Acta Orthopaedica Scandinavica, Supplement. 2004; 75:11-5.

[2] Ratasvuori M, Wedin R, Keller J, et al. Insight opinion to surgically treated metastatic bone disease: Scandinavian Sarcoma Group Skeletal Metastasis Registry report of 1195 operated skeletal metastasis. Surgical Oncology. 2013; 22:132-8.

[3] Mavrogenis AF, Pala E, Romagnoli C, Romantini M, Calabro T, Ruggieri P. Survival analysis of patients with femoral metastases. Journal of Surgical Oncology. 2012; 105:135-41. [4] Weiss RJ, Wedin R. Surgery for skeletal metastases in lung cancer. Acta Orthopaedica. 2011; 82:96-101.

[5] Anesthesiologists ASo. ASA Physical Status Classification System. Edition.: American Society of Anesthesiologists, [updated 15 October 2014; cited 15 June 2015.Available from: http://www.asahq.org/resources/clinical-information/asa-physical-status-classificationsystem

[6] Dijstra S, Wiggers T, van Geel BN, Boxma H. Impending and actual pathological fractures in patients with bone metastases of the long bones. A retrospective study of 233

This article is protected by copyright. All rights reserved. 
surgically treated fractures. The European Journal Of Surgery = Acta Chirurgica. 1994; 160:535-42.

[7] Fottner A, Szalantzy M, Wirthmann L, et al. Bone metastases from renal cell carcinoma: Patient survival after surgical treatment. BMC Musculoskeletal Disorders. 2010; 11.

[8] Weiss RJ, Forsberg JA, Wedin R. Surgery of skeletal metastases in 306 patients with prostate cancer. Acta Orthopaedica. 2012; 83:74-9.

[9] Wegener B, Schlemmer M, Stemmler J, Jansson V, Durr HR, Pietschmann MF. Analysis of orthopedic surgery of bone metastases in breast cancer patients. BMC Musculoskeletal Disorders. 2012; 13.

[10] Utzschneider S, Wicherek E, Weber P, Schmidt G, Jansson V, Durr HR. Surgical treatment of bone metastases in patients with lung cancer. International Orthopaedics. 2011; 35:731-6.

[11] Böhm P, Huber J. The surgical treatment of bony metastases of the spine and limbs. The Journal Of Bone And Joint Surgery British Volume. 2002; 84:521-9.

[12] Schneiderbauer MM, von Knoch M, Schleck CD, Harmsen WS, Sim FH, Scully SP. Patient survival after hip arthroplasty for metastatic disease of the hip. The Journal Of Bone And Joint Surgery American Volume. 2004; 86-A:1684-9.

[13] Weiss RJ, Tullberg E, Forsberg JA, Bauer HC, Wedin R. Skeletal metastases in 301 breast cancer patients: patient survival and complications after surgery. Breast (Edinburgh, Scotland). 2014; 23:286-90.

[14] Wedin R, Falkenius J, Weiss RJ, Hansson J. Surgical treatment of skeletal metastases in 31 melanoma patients. Acta Orthopaedica Belgica. 2012; 78:246-53.

[15] Nathan SS, Chan L, Tan WL, et al. The need for a system of prognostication in skeletal metastasis to decide best end-of-life care - a call to arms. Annals of The Academy Of Medicine, Singapore. 2010; 39:476-81.

[16] Satcher RL, Lin P, Harun N, Feng L, Moon BS, Lewis VO. Surgical management of appendicular skeletal metastases in thyroid carcinoma. International Journal of Surgical Oncology. 2012; 2012:417086-.

\section{(}

Figure 1. Metastatic Location

Figure 1 represents the metastatic location of lesions in the upper limb (A) and lower limb (B).

\section{Figure 2. Metastatic Histotypes}

Figure 2 describes the different metastatic histotypes represented in this patient cohort. 


\section{Figure 3. Survival Rates}

Figure 3 shows the Kaplan-Meier Survival Estimate.

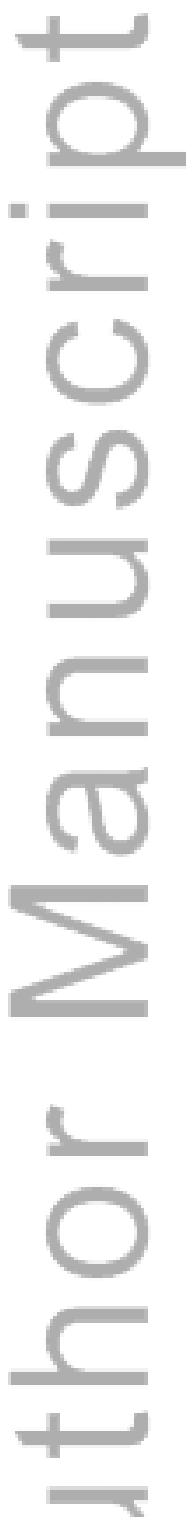

Table 1. Univariate Analysis

Table 1 represents the unadjusted analysis.

Variable Hazard Ratio $\quad$ P Value $\quad 95 \%$

This article is protected by copyright. All rights reserved. 


\begin{tabular}{|c|c|c|c|}
\hline & & & $\begin{array}{l}\text { Confidence } \\
\text { Interval }\end{array}$ \\
\hline \multicolumn{4}{|l|}{ Metastatic Histotype } \\
\hline Breast & 0.700 & 0.001 & $0.6-0.9$ \\
\hline Gastrointestinal & 1.180 & 0.408 & $0.8-1.7$ \\
\hline Gynaecological & 0.477 & 0.021 & $0.3-0.9$ \\
\hline Haematological & 0.800 & 0.533 & $0.4-1.6$ \\
\hline Lung & 2.622 & 0.000 & $2.0-3.4$ \\
\hline Prostate & 1.545 & 0.017 & $1.1-2.2$ \\
\hline Renal & 0.782 & 0.110 & $0.6-1.1$ \\
\hline Skin & 0.859 & 0.387 & $0.6-1.2$ \\
\hline \multicolumn{4}{|l|}{ Gender } \\
\hline Male & 1.373 & 0.002 & $1.1-1.7$ \\
\hline Female (Ref) & 1.00 & & \\
\hline \multicolumn{4}{|l|}{ Age at diagnosis } \\
\hline e 65 years & 1.253 & 0.027 & $1.0-1.5$ \\
\hline$<65$ years $($ Ref) & 1.00 & & \\
\hline ASA 1 & 0.310 & 0.101 & $0.1-1.3$ \\
\hline ASA 2 & 0.578 & 0.003 & $0.4-0.8$ \\
\hline ASA 3 & 0.807 & 0.099 & $0.6-1.0$ \\
\hline ASA 4 (Ref) & 1.00 & & \\
\hline \multicolumn{4}{|l|}{ Pathological Fracture } \\
\hline Yes & 1.572 & 0.000 & $1.3-1.9$ \\
\hline No (Ref) & 1.00 & & \\
\hline \multicolumn{4}{|l|}{ Previous Adjuvant Therapy } \\
\hline Combined & 1.557 & 0.000 & $1.2-2.0$ \\
\hline Radiotherapy & 1.136 & 0.364 & $0.9-1.5$ \\
\hline Chemotherapy & 1.193 & 0.334 & $0.8-1.7$ \\
\hline Nil (Ref) & 1.00 & & \\
\hline
\end{tabular}

This article is protected by copyright. All rights reserved. 


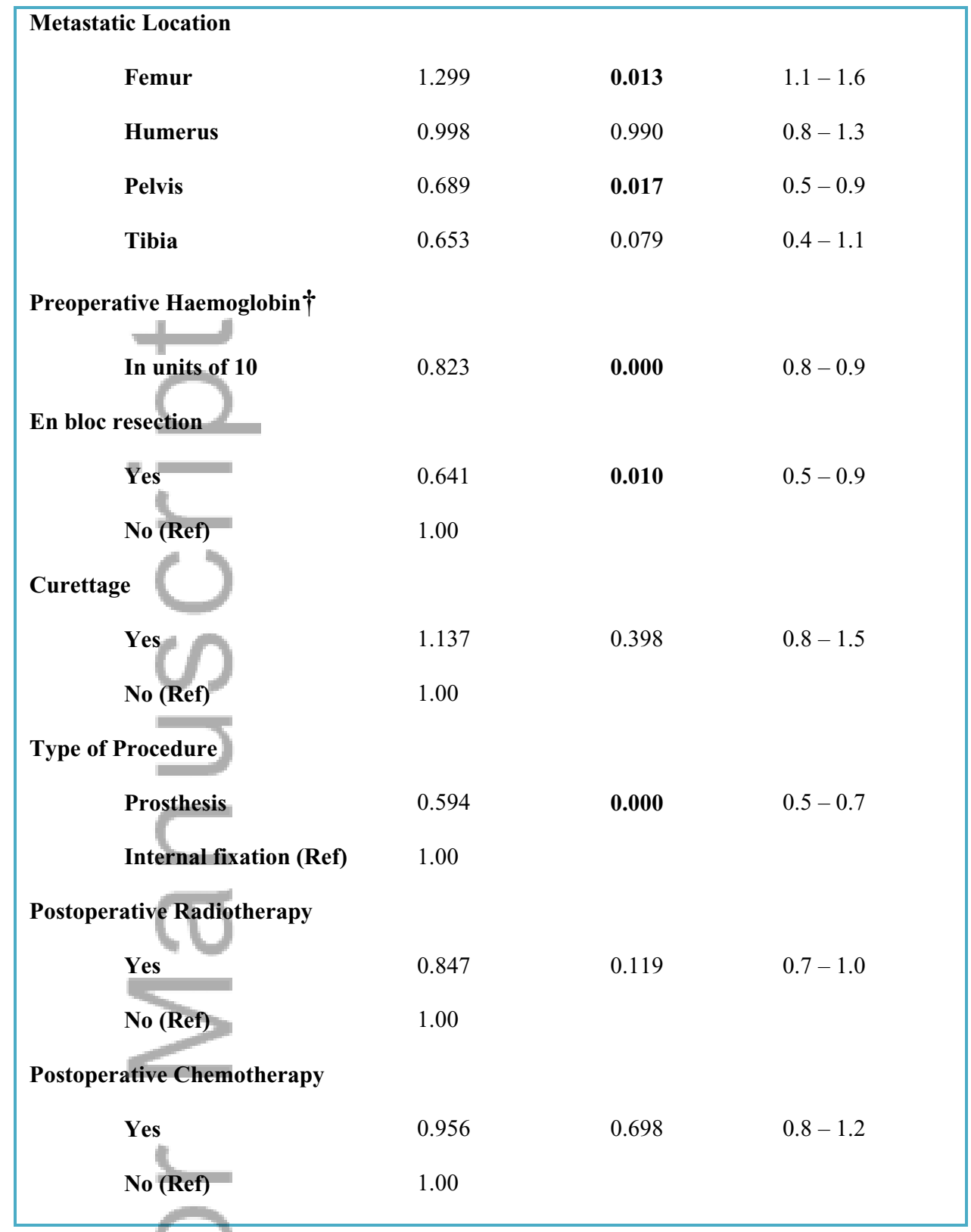

$\dagger$ Variable data was complete for 428 of the original 460 patients.

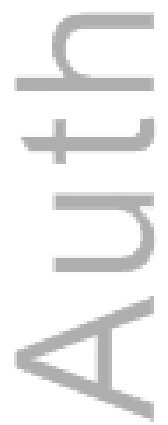

This article is protected by copyright. All rights reserved. 


\section{Table 2. Multivariate Analysis}

Table 2 represents the adjusted analysis There were 428 observations in the adjusted analysis.

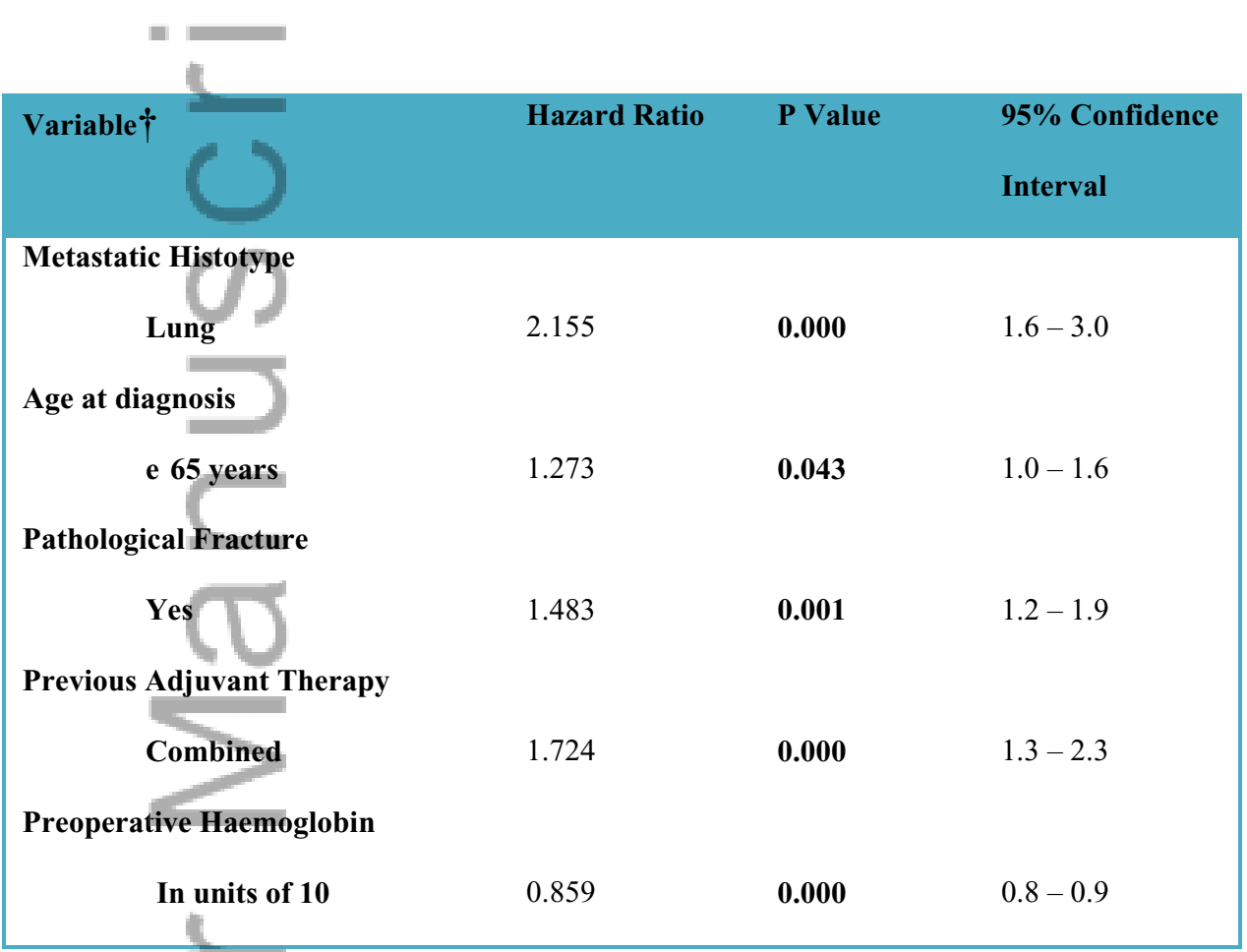

$\dagger$ Variables found to be non-significant are not shown. These include breast, gynaecological and prostate histotypes, gender, ASA score, pelvis and femur locations, En bloc resection and type of procedure.

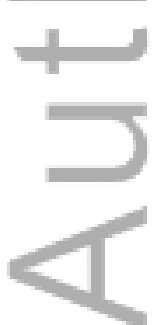

This article is protected by copyright. All rights reserved. 


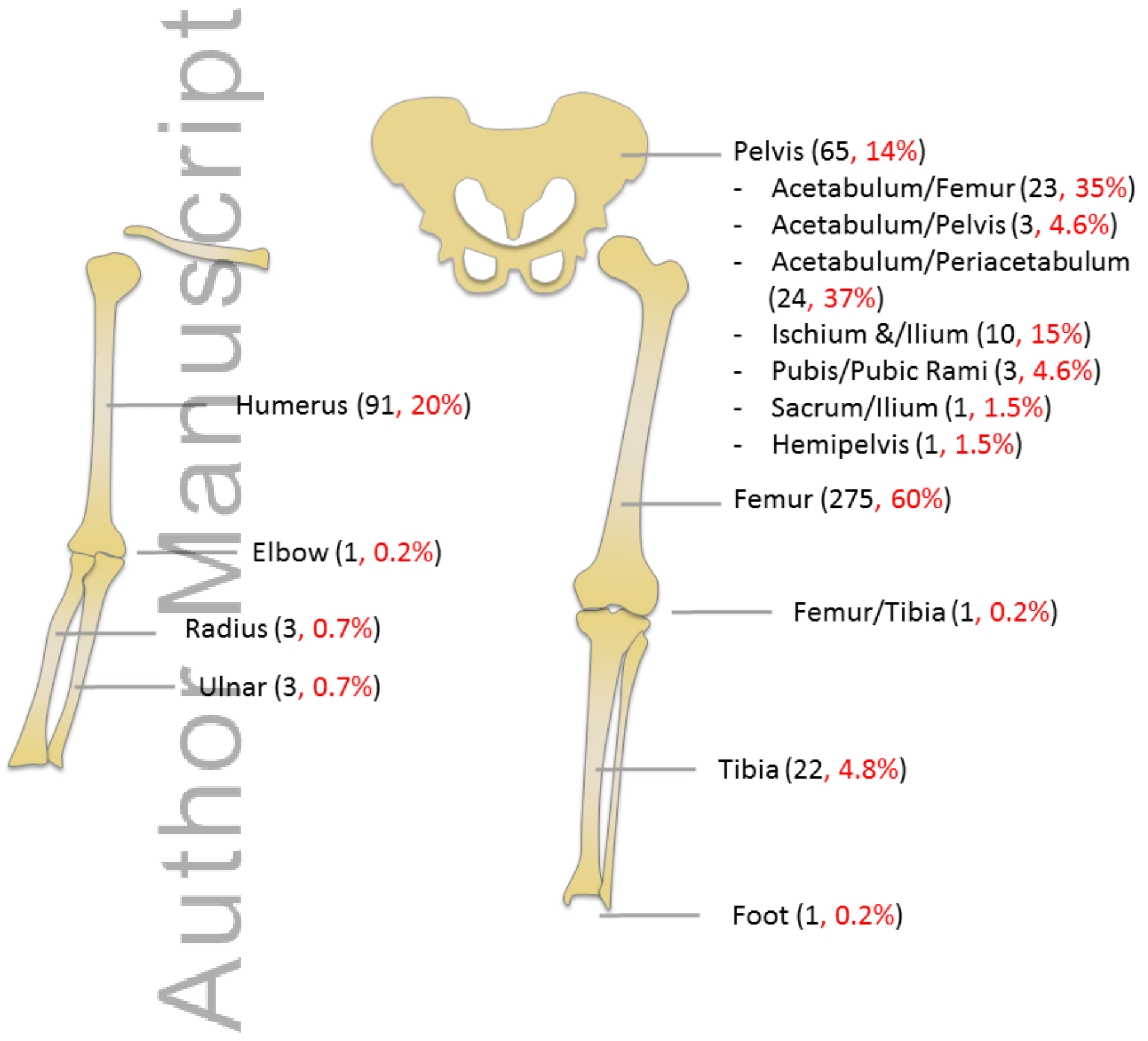




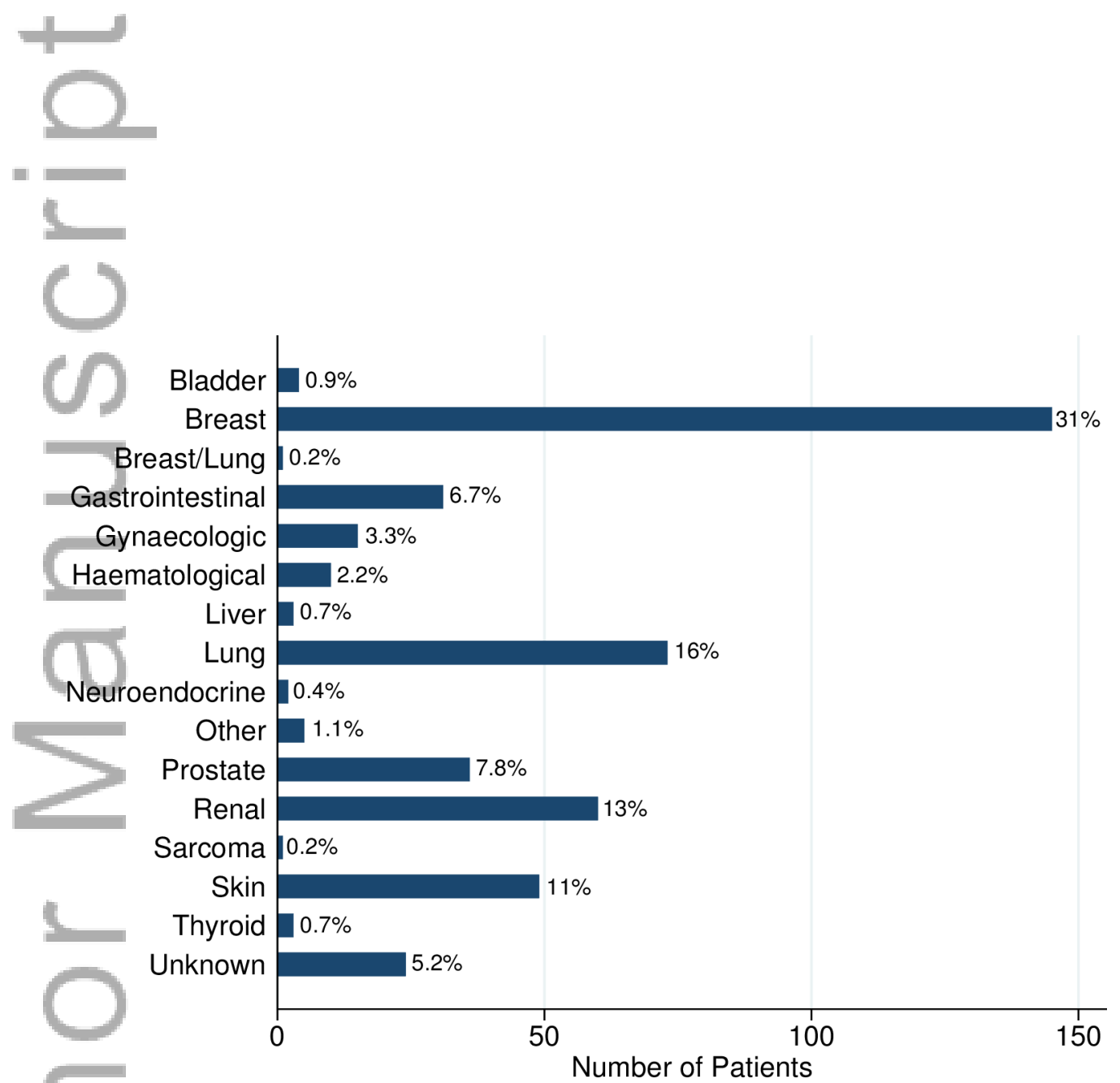

figure 2. metastatic histotypes

This article is protected by copyright. All rights reserved. 


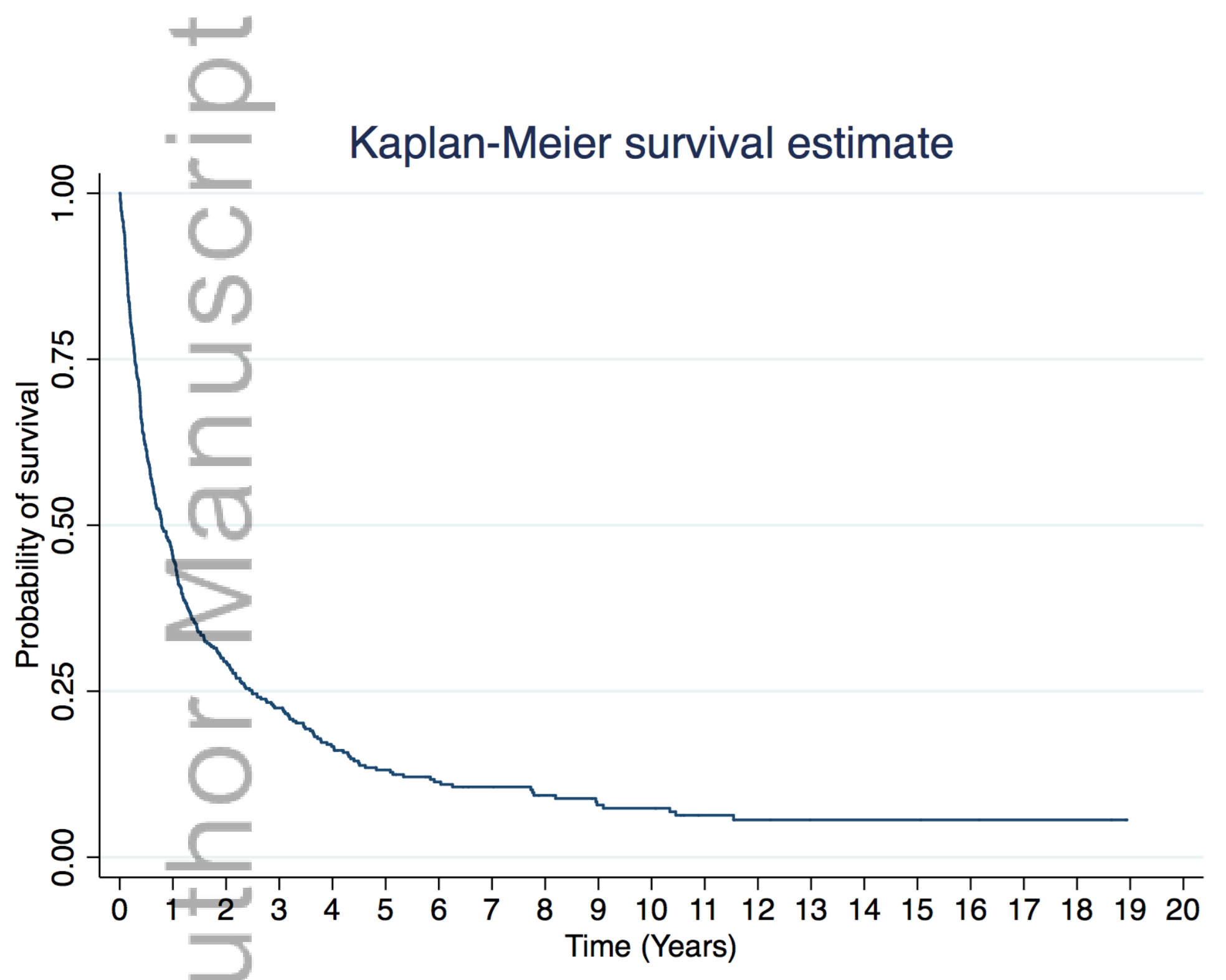

Figure 3 Survival Rates.tif 


\section{University Library}

\section{- M M N E R VA A gateway to Melbourne's research publications}

Minerva Access is the Institutional Repository of The University of Melbourne

Author/s:

Kirkinis, MN;Spelman, T;May, D;Choong, PFM

Title:

Metastatic bone disease of the pelvis and extremities: rationalizing orthopaedic treatment

Date:

2017-11-01

Citation:

Kirkinis, M. N., Spelman, T., May, D. \& Choong, P. F. M. (2017). Metastatic bone disease of the pelvis and extremities: rationalizing orthopaedic treatment. ANZ JOURNAL OF SURGERY, 87 (11), pp.940-944. https://doi.org/10.1111/ans.13615.

Persistent Link:

http://hdl.handle.net/11343/291180 